\title{
$\mu$-Opioid Receptor Gene A118G Polymorphism Predicts Survival in Patients with Breast Cancer
}

\author{
Andrey V. Bortsov, M.D., Ph.D.[Assistant Professor], \\ Department of Anesthesiology, University of North Carolina at Chapel Hill \\ Robert C. Millikan, D.V.M., Ph.D.[Professor], \\ Department of Epidemiology, University of North Carolina at Chapel Hill \\ Inna Belfer, M.D., Ph.D.[Associate Professor], \\ Department of Anesthesiology, University of Pittsburg \\ Richard L. Boortz-Marx, M.D.[Associate Professor], \\ Department of Anesthesiology, University of North Carolina at Chapel Hill \\ Harendra Arora, M.D.[Associate Professor], and \\ Department of Anesthesiology, University of North Carolina at Chapel Hill
}

Samuel A. McLean, M.D., M.P.H.[Assistant Professor]

Department of Anesthesiology, University of North Carolina at Chapel Hill

\section{Abstract}

Background-Preclinical studies suggest that opioids may promote tumor growth. Genetic polymorphisms have been shown to affect opioid receptor function and to modify the clinical effects of morphine. In this study we assessed the association between six common polymorphisms in the $\mu$-opioid receptor gene, including the well known A118G polymorphism, and breast cancer survival.

Methods-A total of 2,039 women ages 23-74 yr (38\% African American, 62\% European American, 55\% postmenopausal) diagnosed with breast cancer between $1993-2001$ were followed through 2006. Genotyping was performed using the TaqMan platform (Applied Biosystems Inc., Foster City, CA). Kaplan-Meyer curves, log-rank tests, and Cox proportional hazard models were used to examine the association between each genotype and survival.

Results-After Bonferroni adjustment for multiple testing, patient genotype at A118G was associated with breast cancer-specific mortality at $10 \mathrm{yr}$. Women with one or more copies of the $\mathrm{G}$ allele had decreased breast cancer-specific mortality $(p<.001)$. This association was limited to invasive cases only; effect size appeared to increase with clinical stage. Cox regression model adjusted for age and ethnicity also showed decreased mortality in $\mathrm{A} / \mathrm{G}$ and $\mathrm{G} / \mathrm{G}$ genotypes compared to $\mathrm{A} / \mathrm{A}$ genotype (hazard ratio $=0.57[0.38,0.85]$ and $0.32[0.22,0.49]$, respectively; $p$ $=.006)$.

Corresponding author: Andrey Bortsov, M.D., Ph.D., Department of Anesthesiology, The University of North Carolina at Chapel Hill; Address: N2201 UNC Hospitals CB 7010, Chapel Hill, NC 27599-7010, abortsov@aims.unc.edu; Phone: 919-843-5353; Fax: 919-966-7193.

Department and institution: Department of Anesthesiology, University of North Carolina at Chapel Hill

Disclosure of funding: This work was funded by the Specialized Program of Research Excellence in Breast Cancer (grant P50CA58223, National Institutes of Health/National Cancer Institute, Bethesda, Maryland) and the research funds from the Department of Anesthesiology, University of North Carolina at Chapel Hill (Chapel Hill, North Carolina). 
Conclusions-These results suggest that opioid pathways may be involved in tumor growth. Further studies examining the association between genetic variants influencing opioid system function and cancer survival are warranted.

\section{INTRODUCTION}

$\mu$-Opioid receptor activation by endogenous opioids (e.g., endorphins) or exogenous opioids (e.g., morphine) results in analgesia. ${ }^{1}$ Importantly, in addition to this well known analgesic effect, $\mu$-opioid receptor activation has other less well known effects that may influence tumor growth and cancer progression. ${ }^{2}$ Stimulation of $\mu$-opioid receptors on endothelial cells results in angiogenesis. ${ }^{3-6}$ In addition, opioids appear to suppress a number of aspects of immune system function, and some of these effects have been shown to be mediated by $\mu$-opioid receptor activation (reviewed in ${ }^{7}$ ). For example, stimulation of $\mu$-opioid receptors on immune cells reduces macrophage and lymphocyte proliferation and cytokine secretion. ${ }^{8-11}$ Activation of $\mu$-opioid receptors in brainstem regions modulates hypothalamic-adrenal-pituitary axis function and increases peripheral glucocorticoids, ${ }^{12}$ which may compromise immune function and promote tumor growth. ${ }^{13,14}$ Preclinical studies ${ }^{15,16}$ and limited human data (reviewed in ${ }^{17}$ ) have implicated opioid pathways in the progression of several different types of cancer.

If $\mu$-opioid receptor activation mediates processes which influence tumor growth, then naturally occurring genetic variations which affect $\mu$-opioid receptor function would be expected to be associated with differences in cancer progression, and ultimately survival, in cancer patients. A number of functional genetic variants have been identified within $\mu$ opioid receptor gene. ${ }^{18}$ The most common and well known genetic variant is the single nucleotide polymorphism (SNP) A118G. The G allele results in reduced receptor transcription and response to opioid receptor binding. ${ }^{19}$ Individuals with one or more $\mathrm{G}$ alleles ( 30\% of European Americans and 7\% of African Americans according to HapMap database) have been found to have a reduced analgesic response to opioids. ${ }^{20-23}$

In this study we explored the association between common polymorphisms in the $\mu$-opioid receptor gene, including a functional A118G SNP, and breast cancer survival. With regard to $\mathrm{A} 118 \mathrm{G}$, we hypothesized that individuals with one or more copies of the (low-response) $\mathrm{G}$ allele would experience increased breast cancer survival.

\section{MATERIALS AND METHODS}

The cohort of cancer female patients evaluated in this study came from the Carolina Breast Cancer Study; the methodology of this study is described in detail elsewhere. ${ }^{24}$ In brief, new cases of breast cancer from 24 counties of North Carolina diagnosed between 1993 and 2001 were identified using rapid case ascertainment. Written informed consent was obtained upon recruitment. An in-home interview was performed that included blood sample collection, information on menopausal status, and an assessment of other potential covariates. Ethnicity was determined by self-report questions during the interview; only African Americans or European Americans were eligible for recruitment. Data on estrogen receptor status and tumor stage at diagnosis were obtained from patient medical records. Subsequent patient survival outcomes were determined using National Death Index (NDI) data.

NDI search was performed using the standard criteria as suggested in the NDI User's Guide.* An NDI record would match a submitted record if any of the following seven criteria were met: 1) social security number (SSN); 2) first and last name, exact month of

\footnotetext{
*Available at http://www.cdc.gov/nchs/data_access/ndi/ndi_user_guide.htm; last time accessed on May 9, 2010.
} 
birth, year of birth within $1 \mathrm{yr}$; 3) last name, first initial and middle initial, exact month of birth, year of birth within $1 \mathrm{yr}$; 4) first and last name, exact month of birth, exact day of birth; 5) last name, first initial and middle initial, exact month of birth, exact day of birth; 6) first name, father's surname, exact month of birth, exact year of birth; 7) for females only, first name, exact month and year of birth, and last name from the submitted record matching birth surname on the NDI record. As a result of the search, none, one, or more NDI records could be matched to a given submitted record. In addition to the variables used in the seven matching criteria, the NDI search returned an indication of agreement for a number of other variables. After the search, each possible match record was assigned a probabilistic match score (the sum of the weights assigned to each of the variables used in the NDI record match). ${ }^{25}$ After scoring the potential matches, each record was categorized into one of five classes: Class 1 (exact match on SSN, first name, middle initial, last names, sex, state of birth, birth month and birth year); Class 2 (SSN matches on at least seven digits and one or more of the other items from Class 1 may not match); Class 3 (SSN unknown but eight or more of first name, middle initial, last name, birth day, birth month, birth year, sex, race, marital status, or state of birth match); Class 4 (Same as Class 3 but less than eight items match); Class 5 (SSN is known but doesn't match). All of Class 1 matches were considered to be true matches; all of the Class 5 matches were considered false matches. Records categorized into one of Classes 2, 3, or 4 were considered either true matches or false matches based on score cut-off points ( 44.5 for Class $2 ; 37.5$ for Class $3 ; 32.5$ for Class 4 ). The sensitivity of NDI search is estimated to be $98 \%$ and specificity approximately $100 \%{ }^{26}$ After a match was obtained, date of death and cause of death were obtained from the NDI record for each deceased individual. Cause of death was classified as breast cancer-specific if the first listed underlying cause of death had International Classification of Disease codes 174.9 (version 9) or 50.9 (version 10).

DNA was extracted from peripheral blood lymphocytes by standard methods using an automated Nucleic Acid Purification System ABI-DNA extractor (Applied Biosystems, Inc., Foster City, CA), and subsequently stored prior to study analyses. For this study, we chose to examine the association between breast cancer survival and A118G SNP (rs1799971, located within the first exon) and five other informative SNPs within other parts of the $\mu$ opioid receptor gene OPRM1 (first intron (rs495491, rs563649), second intron (rs2075572), third intron (rs533586), and fifth exon (3'-untranslated region) (rs609148)). ${ }^{18}$ Genotyping was performed using the TaqMan platform (Applied Biosystems, Inc.). Genotyping was repeated on a $10 \%$ random sample of participants. There was $100 \%$ call agreement between original and repeat genotyping. Institutional Review Board at the University of North Carolina at Chapel Hill (Chapel Hill, North Carolina) approval was obtained prior to the data collection and genetic analyses.

The Carolina Breast Cancer Study was designed as a case-control study. In addition to women with breast cancer, population-based controls were selected using a Division of Motor Vehicles registry for women younger than $65 \mathrm{yr}$ and a Health Care Financing Administration (now the Centers for Medicare and Medicaid Services) registry for women 65-74 yr of age. The sampling fractions were designed to ensure frequency-matching to cases by race and 5-yr age group. In this study, healthy controls were also genotyped in order to assess Hardy-Weinberg equilibrium and linkage disequilibrium for the six genotypes evaluated. Controls were used for these analyses rather than cases to avoid potential selection bias. ${ }^{27}$

\section{Statistical analyses}

Descriptive statistics were obtained for sociodemographic and clinical characteristics of the sample. Individual SNP and genotype frequencies for each locus were evaluated. HardyWeinberg equilibrium and linkage disequilibrium between loci were evaluated in healthy 
participants from the Carolina Breast Cancer Study control group using Haploview software (Broad Institute of Massachusetts Institute of Technology and Harvard, Cambridge, MA). , 28

For the purpose of survival analyses, individuals with breast cancer living at December 31, 2006 and individuals who died of causes other than breast cancer were censored. Breast cancer-specific survival was estimated using Kaplan-Meier method, stratified by ethnicity and stage at diagnosis. The log-rank test was used to compare survival curves between genotype groups. Bonferroni correction was applied to the significance level for the six genotypes assessed to preserve an overall false positive rate of $\alpha=.05$. Within genotype A118G, subgroup analyses stratified by ethnicity and cancer stage were performed using significance level $\alpha=.05$.

Cox proportional hazards regression models were used to evaluate the effect of genotype on breast cancer-specific survival, adjusted for potential confounders. The proportional hazards assumption was tested using log-log survival plots and the Schoenfeld residuals approach. ${ }^{29}$ All analyses, unless otherwise noted, were performed using SAS (version 9.2, SAS Institute Inc., Cary, NC).

\section{RESULTS}

Characteristics of the breast cancer patient cohort are shown in table 1. A total of 2039 women (766 African Americans and 1,273 European Americans) were included in the analyses. Invasive breast cancer cases constituted $77 \%$. Median follow up period was $9 \mathrm{yr}$. All six polymorphisms were genotyped with success rates $\geq 98 \%$. All six polymorphisms were in Hardy-Weinberg equilibrium and moderate-to-high linkage disequilibrium (fig. 1).

After Bonferroni correction for multiple comparisons, the A118G genotype was significantly associated with breast cancer-specific mortality (table 2). Breast cancerspecific mortality was reduced in women with one or two copies of the G-allele (table 2). Analyses stratified by ethnicity, although not reaching statistical significance, revealed the same direction of effect for both African Americans and European Americans (table 3). Women with at least one copy of $\mathrm{G}$ allele had lower mortality than those with A/A genotype (table 3). Analysis stratified by stage at diagnosis (table 4, fig. 2) revealed that this effect was limited to invasive cases only (stages I-IV), with effect size increasing with cancer stage at diagnosis. No other polymorphisms were associated with breast cancer survival (table 2).

A118G genotype was also associated with breast cancer stage at diagnosis. Women who presented at a more advanced stage (III-IV) were less likely to have one or more copies of the $\mathrm{G}$ allele than women who presented at an earlier stage (I-II) or with carcinoma in situ. These differences reached significance in European Americans (Cochran-Armitage trend test $p=.046$ ), but not in African Americans ( $p=.53$ ) (table 5). A118G was not associated with estrogen receptor status (data not shown).

Because the results from the crude and stratified survival analyses suggest that the effect of A118G genotype is a linear function of the number of $G$ alleles, we ran a set of Cox proportional hazard regression models with the predictor variable representing the number of $\mathrm{G}$ alleles at A118G, a so called additive genetic model. The proportional hazard assumption was violated for cancer stage at diagnosis $(p=.005)$. The full Cox model included interaction terms for A118G genotype x stage and for A118G genotype $\mathrm{x}$ ethnicity.

*Available for download at http://www.broad.mit.edu/mpg/haploview/; last time accessed on August 15, 2011. 
Neither of these interaction terms were significant (data not shown), therefore they were excluded from further models. Because inclusion of postmenopausal and ER status did not change the hazard ratio estimates for A118G genotype, and because A118 genotype was associated with cancer stage at presentation, the final model included only age and ethnicity (table 6, model 1). The association between A118G genotype and breast cancer survival remained statistically significant $(p=.006)$.

As a sensitivity analysis we repeated the survival analyses using all-cause mortality as an outcome. The results were yielded the same findings (data not shown).

\section{DISCUSSION}

In this study we found that breast cancer-specific mortality was significantly reduced in patients with a genetic variant in the $\mu$-opioid receptor which reduces opioid response. Tenyear mortality was reduced in patients with at least one variant G allele at A118G. The protective effect of this polymorphism was limited to invasive cases only and appeared to increase with stage at diagnosis. Decreased mortality with one or more $\mathrm{G}$ alleles was observed in both African Americans and European Americans, although the association did not reach statistical significance in stratified analyses. Having one or more $\mathrm{G}$ alleles was also associated with having less advanced disease at diagnosis.

Our results are consistent with a post-hoc analysis of data from a longitudinal study of traditional high dose systemic opioid treatment versus opioid treatment delivered directly into the intrathecal space (low systemic opioid exposure) via an implantable drug delivery system. ${ }^{30}$ This trial was designed to assess symptomatic outcomes, but a post-hoc analysis, although statistically nonsignificant, suggested increased survival in the implantable drug delivery system group at 6 months $(54 \% v s .37 \%, p=.06){ }^{30}$

Other studies have examined the effect of reduced opioid exposure during the perioperative period on cancer outcomes, with mixed effects. Two retrospective studies of cancer patients found a reduced risk of tumor recurrence and metastasis in cases where an opioid-sparing perioperative regimen was used. ${ }^{31,32}$ Another study observed this benefit only in patients 65 $\mathrm{yr}$ of age or older, ${ }^{33}$ and a secondary analysis of a randomized controlled study showed no difference. ${ }^{34}$ If opioids influence tumor growth in an ongoing manner via direct (e.g., angiogenic) and/or indirect (immune function) mechanisms, then combined interventions which reduce both perioperative opioid exposure and longitudinal opioid exposure after hospital discharge (e.g., via peripherally acting opioid antagonists or implantable drug delivery systems) may achieve the most benefit.

In our study, the presence of a $\mathrm{G}$ allele at $\mathrm{A} 118 \mathrm{G}$ appeared to result in improved survival in both European Americans and African Americans, although the association did not reach statistical significance in stratified analyses. Of note, available data suggests that the $\mathrm{G}$ allele is less prevalent in African Americans than in European Americans (minor allele frequency of 0.04 vs. 0.16, HapMap database). If having a $\mathrm{G}$ allele is indeed associated with increased breast cancer survival, then ethnic differences at $\mathrm{A} 118 \mathrm{G}$ could contribute to the reduced breast cancer survival observed in African Americans. ${ }^{35,36}$

A limitation of our study is that data on treatment, including opioid intake among study participants was not available. The extent to which any effect of opioids on cancer survival is mediated by endogenous versus exogenous opioids is unknown. However, limited available evidence suggests that endogenous opioids may play an important role. A preclinical study found that baseline levels of endogenous opioids were elevated more than two fold in animals with cancer compared to controls, ${ }^{37}$ suggesting that cancer patients may experience chronic increases in endogenous opioids due to pain, stress, or other causes. In 
addition, a recent study found that, unlike wild type mice, $\mu$-opioid receptor-knockout mice exhibited no tumor growth after injection of Lewis lung carcinoma cells. ${ }^{15}$ No exogenous opioids were received by mice in either group, suggesting that an angiogenic or tumor growth promoting effect was facilitated by stimulation of the mu-opioid receptor by endogenous opioids alone.

As with any gene association study, another limitation of this study is that it is impossible to know if differences in breast cancer survival are actually due to the A118G mutation. This mutation has been shown to result in reduced transcription ${ }^{19}$ and reduced cellular response to $\mu$-opioid receptor binding. ${ }^{38}$ This demonstrated functional consequence increases the possibility that the $\mathrm{A} 118 \mathrm{G}$ polymorphism may itself cause the biological changes which result in differences in breast cancer survival. However, it may be that the observed association is due to another genetic variation or variations that are associated with A118G. ${ }^{18}$

In addition, another limitation of our study is that it included European American and African American patients only, and assessed only patients with breast cancer. Further studies are needed to confirm the association between A118G and cancer survival in Breast Cancer patients in European Americans and African Americans, and to assess the influence of A118G in other cancer types and in other ethnicities. Importantly, evidence from mechanistic studies in humans suggests that important differences in the influence of genetic variants such as the A118G polymorphism across other ethnicities may exist (e.g., Asian vs. European American ${ }^{39}$ ), perhaps in part due to differences in linkage disequilibrium between A118G and other functional polymorphisms in OPRMI or genetic differences influencing the function of physiologic systems which interact with opioid systems. ${ }^{39}$

Our study used the first underlying cause of death listed in the NDI to determine breast cancer-specific mortality. Evidence suggests that variability may exist in the choice of the condition listed first as the cause of death in the NDI ${ }^{40}$ However, an analysis using allcause mortality yielded the same findings.

Finally, G/G genotype at A118G was uncommon in the studied population, and only one death was observed among 22 participants with this genotype. Therefore, mortality estimates for this group are imprecise as evident from the wide confidence intervals (table 2). Therefore, one should be cautious in making any conclusions regarding the presence of "dose-response" relationship between the number of G alleles at A118G and breast cancer mortality.

To our knowledge, this is the first study examining the association between genetic polymorphisms influencing the function of opioid pathways and cancer survival. ${ }^{41,42} \mathrm{Such}$ studies are one useful means of examining the possible influence of opioid pathways on cancer survival in patients in whom withholding opioids would be unethical. The results of this study provide support for the hypothesis that endogenous and/or exogenous opioids, acting via the $\mu$-opioid receptor, may influence cancer outcomes.

\section{Acknowledgments}

The authors thank Luda Diatchenko, M.D., Ph.D., Associate Professor, Center for Neurosensory Disorders, University of North Carolina at Chapel Hill, North Carolina, for valuable discussions of the results of the study.

\section{References}

1. Waldhoer M, Bartlett SE, Whistler JL. Opioid receptors. Annu Rev Biochem. 2004; 73:953-90. [PubMed: 15189164] 
2. Afsharimani B, Cabot P, Parat MO. Morphine and tumor growth and metastasis. Cancer Metastasis Rev. 2011; 30:225-38. [PubMed: 21267766]

3. Farooqui M, Li Y, Rogers T, Poonawala T, Griffin RJ, Song CW, Gupta K. COX-2 inhibitor celecoxib prevents chronic morphine-induced promotion of angiogenesis, tumour growth, metastasis and mortality, without compromising analgesia. Br J Cancer. 2007; 97:1523-31. [PubMed: 17971769]

4. Gupta K, Kshirsagar S, Chang L, Schwartz R, Law PY, Yee D, Hebbel RP. Morphine stimulates angiogenesis by activating proangiogenic and survival-promoting signaling and promotes breast tumor growth. Cancer Res. 2002; 62:4491-8. [PubMed: 12154060]

5. Poonawala T, Levay-Young BK, Hebbel RP, Gupta K. Opioids heal ischemic wounds in the rat. Wound Repair Regen. 2005; 13:165-74. [PubMed: 15828941]

6. Singleton PA, Lingen MW, Fekete MJ, Garcia JG, Moss J. Methylnaltrexone inhibits opiate and VEGF-induced angiogenesis: Role of receptor transactivation. Microvasc Res. 2006; 72:3-11. [PubMed: 16820176]

7. Roy S, Ninkovic J, Banerjee S, Charboneau RG, Das S, Dutta R, Kirchner VA, Koodie L, Ma J, Meng J, Barke RA. Opioid drug abuse and modulation of immune function: Consequences in the susceptibility to opportunistic infections. J Neuroimmune Pharmacol. 2011; 6:442-65. [PubMed: 21789507]

8. Roy S, Wang J, Kelschenbach J, Koodie L, Martin J. Modulation of immune function by morphine: Implications for susceptibility to infection. J Neuroimmune Pharmacol. 2006; 1:77-89. [PubMed: 18040793]

9. Roy S, Barke RA, Loh HH. Mu-opioid receptor-knockout mice: Role of $\mu$-opioid receptor in morphine mediated immune functions. Brain Res Mol Brain Res. 1998; 61:190-4. [PubMed: 9795212]

10. Szabo I, Rojavin M, Bussiere JL, Eisenstein TK, Adler MW, Rogers TJ. Suppression of peritoneal macrophage phagocytosis of Candida albicans by opioids. J Pharmacol Exp Ther. 1993; 267:7036. [PubMed: 8246144]

11. Wang J, Barke RA, Ma J, Charboneau R, Roy S. Opiate abuse, innate immunity, and bacterial infectious diseases. Arch Immunol Ther Exp (Warsz). 2008; 56:299-309. [PubMed: 18836861]

12. Bart G, LaForge KS, Borg L, Lilly C, Ho A, Kreek MJ. Altered levels of basal cortisol in healthy subjects with a $118 \mathrm{G}$ allele in exon 1 of the Mu opioid receptor gene. Neuropsychopharmacology. 2006; 31:2313-7. [PubMed: 16794569]

13. Ben-Eliyahu S. The promotion of tumor metastasis by surgery and stress: Immunological basis and implications for psychoneuroimmunology. Brain Behav Immun. 2003; 17(Suppl 1):S27-36. [PubMed: 12615183]

14. Dietrich K, Schned A, Fortuny J, Heaney J, Marsit C, Kelsey KT, Karagas MR. Glucocorticoid therapy and risk of bladder cancer. Br J Cancer. 2009; 101:1316-20. [PubMed: 19773763]

15. Mathew B, Lennon FE, Siegler J, Mirzapoiazova T, Mambetsariev N, Sammani S, Gerhold LM, LaRiviere PJ, Chen CT, Garcia JG, Salgia R, Moss J, Singleton PA. The novel role of the $\mu$ opioid receptor in lung cancer progression: A laboratory investigation. Anesth Analg. 2011; 112:558-67. [PubMed: 21156980]

16. Boehncke S, Hardt K, Schadendorf D, Henschler R, Boehncke WH, Duthey B. Endogenous $\mu$ opioid peptides modulate immune response towards malignant melanoma. Exp Dermatol. 2011; 20:24-8. [PubMed: 20955200]

17. Cata JP, Gottumukkala V, Sessler DI. How regional analgesia might reduce postoperative cancer recurrence. Eur J Pain Suppl. 2011; 5:345-55.

18. Shabalina SA, Zaykin DV, Gris P, Ogurtsov AY, Gauthier J, Shibata K, Tchivileva IE, Belfer I, Mishra B, Kiselycznyk C, Wallace MR, Staud R, Spiridonov NA, Max MB, Goldman D, Fillingim RB, Maixner W, Diatchenko L. Expansion of the human $\mu$-opioid receptor gene architecture: Novel functional variants. Hum Mol Genet. 2009; 18:1037-51. [PubMed: 19103668]

19. Zhang Y, Wang D, Johnson AD, Papp AC, Sadee W. Allelic expression imbalance of human $\mu$ opioid receptor (OPRM1) caused by variant A118G. J Biol Chem. 2005; 280:32618-24. [PubMed: 16046395] 
20. Fukuda K, Hayashida M, Ide S, Saita N, Kokita Y, Kasai S, Nishizawa D, Ogai Y, Hasegawa J, Nagashima M, Tagami M, Komatsu H, Sora I, Koga H, Kaneko Y, Ikeda K. Association between OPRM1 gene polymorphisms and fentanyl sensitivity in patients undergoing painful cosmetic surgery. Pain. 2009; 147:194-201. [PubMed: 19783098]

21. Hayashida M, Nagashima M, Satoh Y, Katoh R, Tagami M, Ide S, Kasai S, Nishizawa D, Ogai Y, Hasegawa J, Komatsu H, Sora I, Fukuda K, Koga H, Hanaoka K, Ikeda K. Analgesic requirements after major abdominal surgery are associated with OPRM1 gene polymorphism genotype and haplotype. Pharmacogenomics. 2008; 9:1605-16. [PubMed: 19018716]

22. Chou WY, Yang LC, Lu HF, Ko JY, Wang CH, Lin SH, Lee TH, Concejero A, Hsu CJ. Association of $\mu$-opioid receptor gene polymorphism (A118G) with variations in morphine consumption for analgesia after total knee arthroplasty. Acta Anaesthesiol Scand. 2006; 50:78792. [PubMed: 16879459]

23. Reyes-Gibby CC, Shete S, Rakvag T, Bhat SV, Skorpen F, Bruera E, Kaasa S, Klepstad P. Exploring joint effects of genes and the clinical efficacy of morphine for cancer pain: OPRM1 and COMT gene. Pain. 2007; 130:25-30. [PubMed: 17156920]

24. O'Brien KM, Cole SR, Tse CK, Perou CM, Carey LA, Foulkes WD, Dressler LG, Geradts J, Millikan RC. Intrinsic breast tumor subtypes, race, and long-term survival in the Carolina Breast Cancer Study. Clin Cancer Res. 2010; 16:6100-10. [PubMed: 21169259]

25. Rogot E, Sorlie P, Johnson NJ. Probabilistic methods in matching census samples to the National Death Index. J Chronic Dis. 1986; 39:719-34. [PubMed: 3734026]

26. Rich-Edwards JW, Corsano KA, Stampfer MJ. Test of the National Death Index and Equifax Nationwide Death Search. Am J Epidemiol. 1994; 140:1016-9. [PubMed: 7985649]

27. Salanti G, Amountza G, Ntzani EE, Ioannidis JP. Hardy-Weinberg equilibrium in genetic association studies: An empirical evaluation of reporting, deviations, and power. Eur J Hum Genet. 2005; 13:840-8. [PubMed: 15827565]

28. Barrett JC, Fry B, Maller J, Daly MJ. Haploview: Analysis and visualization of LD and haplotype maps. Bioinformatics. 2005; 21:263-5. [PubMed: 15297300]

29. Kleinbaum, DG.; Klein, M. Survival analysis: A self-learning text. 2. Springer Verlag; 2005. p. 131-71.

30. Smith TJ, Staats PS, Deer T, Stearns LJ, Rauck RL, Boortz-Marx RL, Buchser E, Catala E, Bryce DA, Coyne PJ, Pool GE. Randomized clinical trial of an implantable drug delivery system compared with comprehensive medical management for refractory cancer pain: Impact on pain, drug-related toxicity, and survival. J Clin Oncol. 2002; 20:4040-9. [PubMed: 12351602]

31. Biki B, Mascha E, Moriarty DC, Fitzpatrick JM, Sessler DI, Buggy DJ. Anesthetic technique for radical prostatectomy surgery affects cancer recurrence: A retrospective analysis. Anesthesiology. 2008; 109:180-7. [PubMed: 18648226]

32. Exadaktylos AK, Buggy DJ, Moriarty DC, Mascha E, Sessler DI. Can anesthetic technique for primary breast cancer surgery affect recurrence or metastasis? Anesthesiology. 2006; 105:660-4. [PubMed: 17006061]

33. Gottschalk A, Ford JG, Regelin CC, You J, Mascha EJ, Sessler DI, Durieux ME, Nemergut EC. Association between epidural analgesia and cancer recurrence after colorectal cancer surgery. Anesthesiology. 2010; 113:27-34. [PubMed: 20508494]

34. Tsui BCH, Rashiq S, Schopflocher D, Murtha A, Broemling S, Pillay J, Finucane BT. Epidural anesthesia and cancer recurrence rates after radical prostatectomy. Can J Anaesth. 2010; 57:10712. [PubMed: 19911247]

35. Holmes L Jr, Opara F, Hossain J. A five-year breast cancer-specific survival disadvantage of African American women. Afr J Reprod Health. 2010; 14:195-200. [PubMed: 21495613]

36. Grann V, Troxel AB, Zojwalla N, Hershman D, Glied SA, Jacobson JS. Regional and racial disparities in breast cancer-specific mortality. Soc Sci Med. 2006; 62:337-47. [PubMed: 16051406]

37. Lee HJ, Lee JH, Lee EO, Kim KH, Lee KS, Lee CH, Nam DW, Kim SH, Ahn KS. Substance P and beta endorphin mediate electroacupuncture induced analgesic activity in mouse cancer pain model. Acupunct Electrother Res. 2009; 34:27-40. [PubMed: 19711773] 
38. Ray R, Ruparel K, Newberg A, Wileyto EP, Loughead JW, Divgi C, Blendy JA, Logan J, Zubieta JK, Lerman C. Human Mu Opioid Receptor (OPRM1 A118G) polymorphism is associated with brain $\mu$-opioid receptor binding potential in smokers. Proc Natl Acad Sci U S A. 2011; 108:926873. [PubMed: 21576462]

39. Hernandez-Avila CA, Covault J, Wand G, Zhang H, Gelernter J, Kranzler HR. Population-specific effects of the Asn40Asp polymorphism at the $\mu$-opioid receptor gene (OPRM1) on HPA-axis activation. Pharmacogenet Genomics. 2007; 17:1031-8. [PubMed: 18004207]

40. Maynard C, Lowy E, McDonell M, Fihn SD. Cause of death in Washington state veterans hospitalized with acute coronary syndromes in the veterans health administration. Popul Health Metr. 2008; 6:3. [PubMed: 18647422]

41. Singleton PA, Moss J. Effect of perioperative opioids on cancer recurrence: A hypothesis. Future Oncol. 2010; 6:1237-42. [PubMed: 20799870]

42. Durieux ME. Does anesthetic management affect cancer outcome. APSF Newsl. 2009; 23:49-51.

43. Gabriel SB, Schaffner SF, Nguyen H, Moore JM, Roy J, Blumenstiel B, Higgins J, DeFelice M, Lochner A, Faggart M. The structure of haplotype blocks in the human genome. Science. 2002; 296:2225-9. [PubMed: 12029063] 


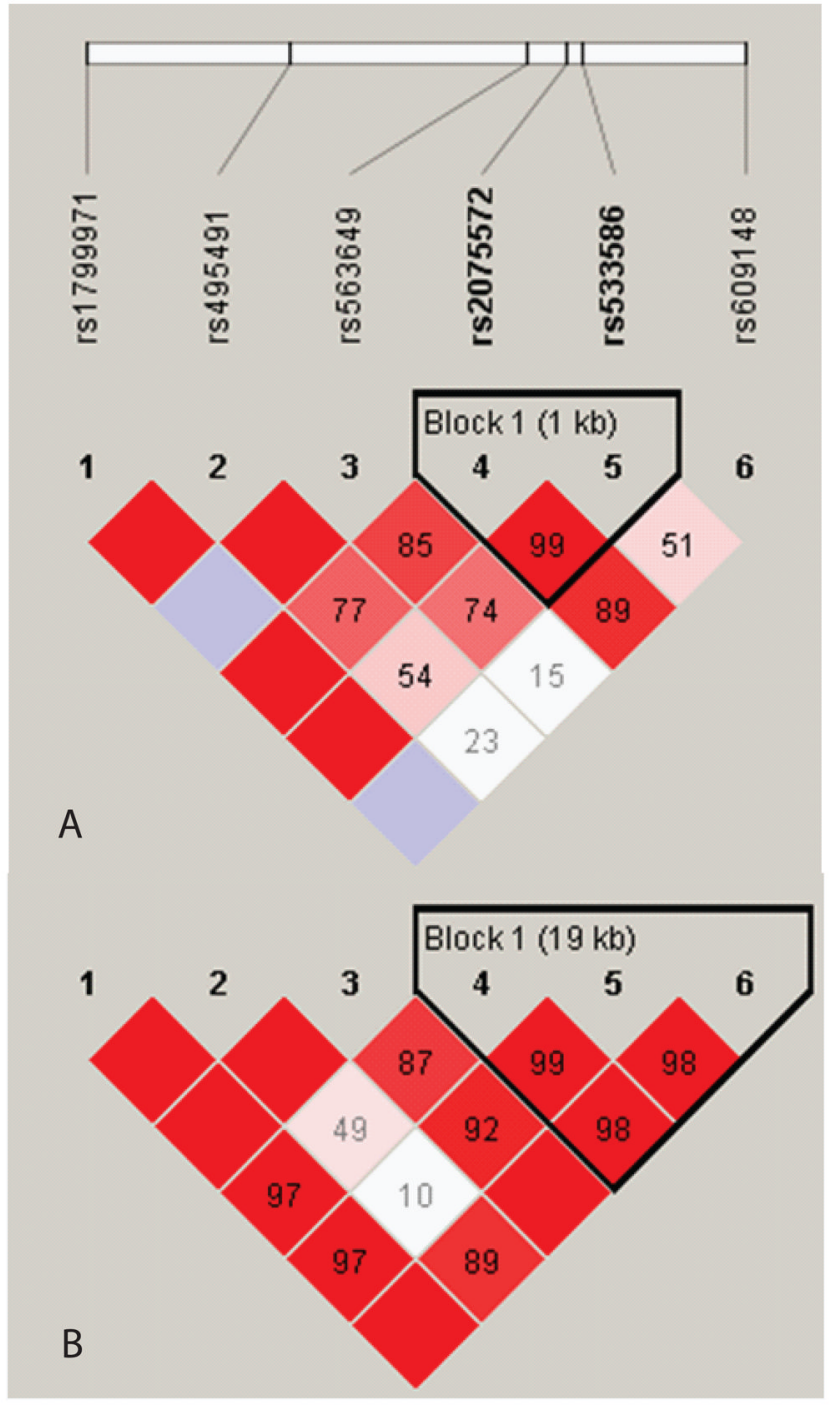

Figure 1.

Linkage disequilibrium plots for 679 African American controls (A) and 1,131 European American controls (B). Color represents D' values (dark red = high inter-SNP D'; blue = statistically ambiguous $\mathrm{D}^{\prime}$; white $=$ low inter-SNP $\mathrm{D}^{\prime}$ ), and $\mathrm{r}^{2}$ values are contained within blocks. Block definitions are calculated using the Gabriel et al. method. ${ }^{43}$ 

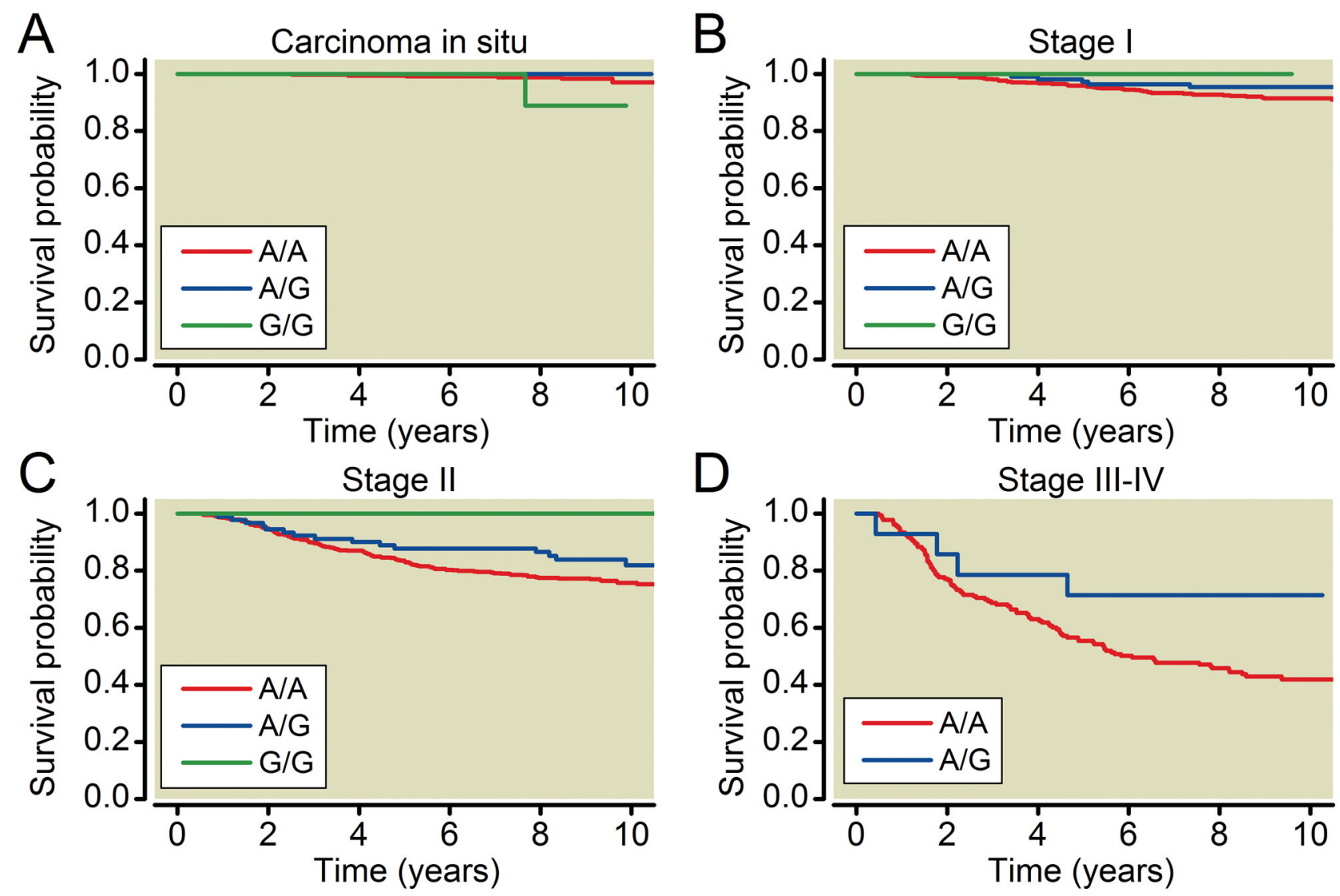

Figure 2.

Kaplan-Meier plots by A118G (rs1799971) genotype and breast cancer stage at diagnosis. 
Table 1

Characteristics of the Carolina Breast Cancer Study cases

\begin{tabular}{|c|c|}
\hline & $N=2039$ \\
\hline \multicolumn{2}{|l|}{ Age, years } \\
\hline Mean (SD) & $51.9(11.7)$ \\
\hline Range & $23-74$ \\
\hline \multicolumn{2}{|l|}{ Ethnicity, n (\%) } \\
\hline African American & $766(38)$ \\
\hline European American & $1,273(62)$ \\
\hline \multicolumn{2}{|l|}{ Menopausal status, n (\%) } \\
\hline Premenopausal & $912(45)$ \\
\hline Postmenopausal & $1,127(55)$ \\
\hline \multicolumn{2}{|c|}{ Stage at diagnosis, $\mathrm{n}(\%)^{*}$} \\
\hline In situ & $451(23)$ \\
\hline \multicolumn{2}{|l|}{ Invasive: } \\
\hline I & $635(33)$ \\
\hline II & $663(34)$ \\
\hline III & $153(8)$ \\
\hline IV & $44(2)$ \\
\hline \multicolumn{2}{|c|}{ Estrogen receptor status, n (\%) } \\
\hline Positive & $1,045(59)$ \\
\hline Negative & $719(41)$ \\
\hline \multicolumn{2}{|l|}{ Follow up period, years } \\
\hline Median & 9.0 \\
\hline Range & $0.4-13.7$ \\
\hline
\end{tabular}




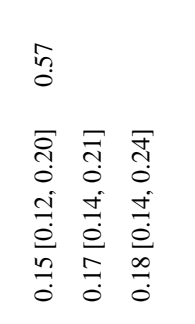

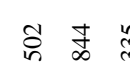
$\infty$ D 8 \& 的空焉

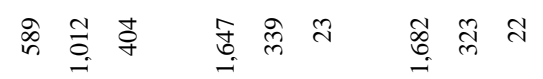
สิ ลั $\bar{\infty}$ इू \&

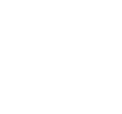




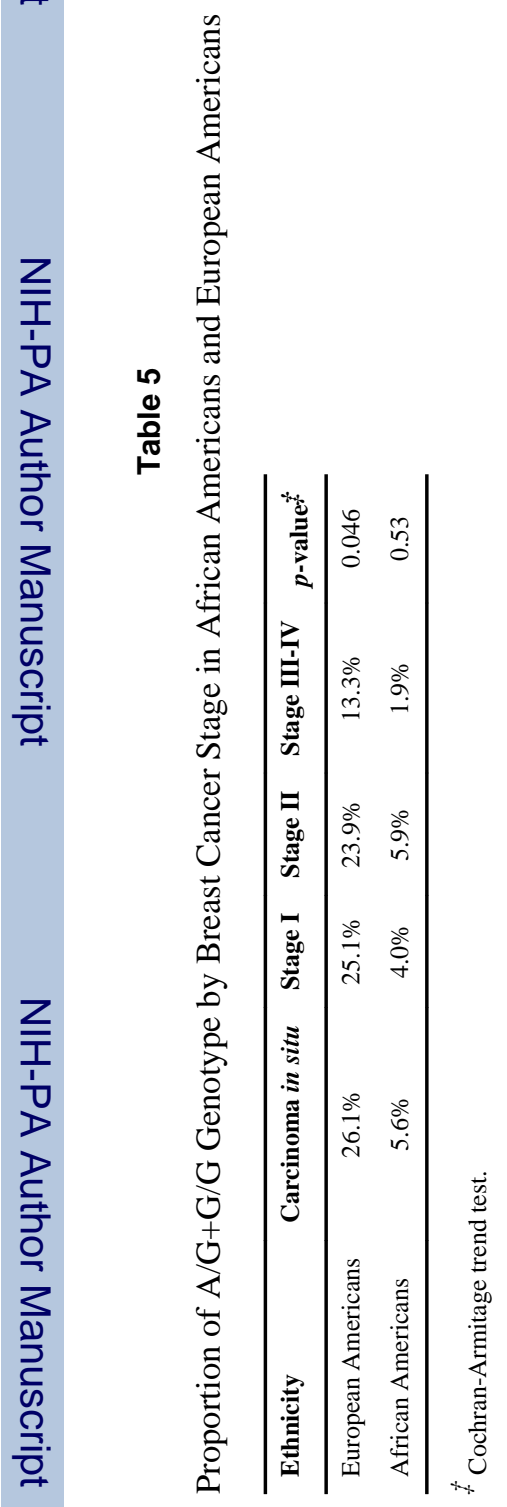


Table 6

Cox Proportional Hazards Regression Analysis for A118G Genotype and Invasive Breast Cancer Mortality

\begin{tabular}{cccc}
\hline & A118G genotype & HR $[\mathbf{9 5 \%} \mathrm{CI}]$ & $\boldsymbol{p}$-value \\
\hline Model 1 $\$$ & $\mathrm{~A} / \mathrm{A}$ & reference & \\
& $\mathrm{A} / \mathrm{G}$ & $0.57[0.38,0.85]$ & 0.006 \\
& $\mathrm{G} / \mathrm{G}$ & $0.32[0.22,0.49]$ & \\
\hline
\end{tabular}

* Additive genetic model was used, where the predictor variable was the number of A alleles at A118G (A/A = 0, A/G = 1, G/G = 2);

$\S$ adjusted for age and race; $\mathrm{CI}=$ confidence interval; $\mathrm{HR}=$ hazard ratio. 